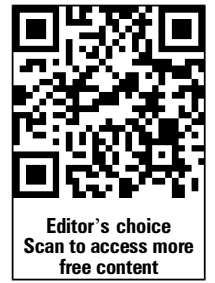

${ }^{1}$ Department of Orthopaedics, Alfred Health, Melbourne, Victoria, Australia

${ }^{2}$ Department of Orthopaedics, Royal Perth Hospital, Perth, Western Australia, Australia ${ }^{3}$ Department of Orthopaedics and Trauma, Royal Perth Hospital, Perth, Western Australia, Australia

\section{Correspondence to}

Dr Charles Alexander Gallagher,

gallaghercharles@hotmail.com

Accepted 16 April 2014

\section{CrossMark}

To cite: Gallagher CA Blakeney W, Zellweger R. BMJ Case Rep Published online: [please include Day Month Year] doi:10.1136/ bcr-2013-203299

\title{
Acromioclavicular joint dislocation with associated brachial plexus injury
}

\author{
Charles Alexander Gallagher, ${ }^{1}$ William Blakeney, ${ }^{2}$ René Zellweger ${ }^{3}$
}

\section{SUMMARY}

We present the case of a 32-year-old female who sustained a left acromioclavicular (AC) joint type $\mathrm{V}$ injury and brachial plexus injury. The patient's AC joint injury was identified 6 days after she was involved in a motorbike accident where she sustained multiple other injuries. She required operative fixation of the $A C$ joint using a locking compression medial proximal tibial plate. At 3 months post operatively, the patient was found to have a subluxed left shoulder as a result of an axonal injury to the upper trunk of the brachial plexus. In addition, the tibial plate had cut out. The plate was subsequently removed. At 8 months the glenohumeral articulation had been restored and the patient had clinically regained significant shoulder function. After 15 months the patient was pain free and could complete all her activities of daily living without impediment. She returned to playing competitive pool after 24 months.

\section{BACKGROUND}

The acromioclavicular (AC) joint is commonly involved in traumatic injuries that affect the shoulder. Injuries to the joint account for approximately $12 \%$ of those to the shoulder girdle seen in clinical practice, ${ }^{1}$ although this is likely to be an underestimate of the true prevalence since patients with minor sprains may not seek medical attention. ${ }^{2}$

The most common cause of AC injury is a force applied directly over the superolateral border of the shoulder, usually during a fall with the humerus adducted. $^{2}$ This force drives the clavicle and acromion inferiorly, with the strong interlocking ligaments at the sternoclavicular joint limiting the amount of inferior displacement of the clavicle. ${ }^{3}$ The greater degree of inferior transposition of the acromion can then lead to rupture of the AC and coracoclavicular ligaments. ${ }^{2}$

Rockwood's group ${ }^{4}$ developed the most widely accepted classification system for AC joint injuries, based on the original work of Tossy et al in $1963 .{ }^{5}$ The classification includes six types of injury to the AC joint that are based on the severity of injury sustained by the AC ligaments and coracoclavicular ligaments in addition to the supporting tissues that include the deltoid and trapezius muscles.

Specifically, type V AC injuries are a more severe version of the type III injury where the attachments of the AC ligaments, coracoclavicular ligament, and the muscle attachments of the deltoid plus trapezius are stripped from the distal clavicle. The clavicle then lies subcutaneously at the displaced AC joint. On plain film, the coracoclavicular space is increased more than $100 \%$ in comparison to the opposite, normal shoulder. ${ }^{6}$

An AC joint injury may be associated with other injuries around the shoulder. These include scapulothoracic dissociation, fractures of the clavicle, the acromion, the coracoid process and the sternoclavicular joint and brachial plexus abnormalities. ${ }^{7}$ There is limited literature on the association between AC joint injury and brachial plexus injury, with few cases described. ${ }^{8-10}$

The appropriate treatment for AC joint injuries has been controversial and continues to evolve.? Using the Rockwood classification, less severe injuries type I-III are generally managed nonoperatively, while type IV and above often require operative management. Specifically, type V injuries require operative reduction and stabilisation because they result in significant deltotrapezial stripping and gross instability, which commonly leads to chronic pain and disability. ${ }^{7}$

In this report, we describe the case of an adult female who experienced a type V AC joint injury with subsequent axonal injury to the upper trunk of the brachial plexus.

\section{CASE PRESENTATION}

A 32-year-old female was injured in a motorbike accident when she collided with a rock at approximately $70 \mathrm{~km} / \mathrm{h}$ on a sealed road. This resulted in her falling off the bike with the bike subsequently falling on to her. She was wearing a helmet and protective jacket. She is right hand dominant, a competitive pool player, and works as an office coordinator.

The patient was resuscitated on arrival at the emergency department. She remained haemodynamically stable. The injuries sustained included: (1) left AC joint type V injury (figure 1); (2) left scapula body fracture; (3) left displaced closed diaphyseal radius and ulna fracture; (4) open book pelvic injury; (5) left renal artery dissection; (6) grade IV splenic laceration; and (7) right thigh full thickness burn $5 \times 3 \mathrm{~cm}$. The patient was treated at the state's trauma unit. The patient's upper and lower limb neurological status was reported as normal throughout her admission.

\section{INVESTIGATIONS}

The patient's left AC joint injury was identified on tertiary survey 6 days after admission. Plain radiographs revealed a type $\mathrm{V}$ AC joint dislocation (figure 1). 


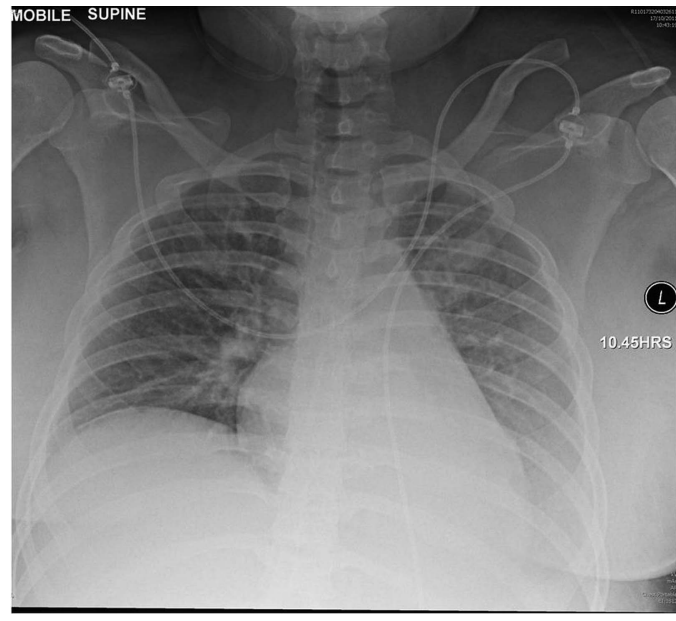

Figure 1 Anterior-posterior chest radiograph demonstrating the left type $\mathrm{V}$ acromioclavicular joint separation with minimally displaced scapular body fracture.

\section{TREATMENT}

Orthopaedic surgery was initially delayed due to her other injuries.

The patient was taken to theatre and given a general anaesthetic. This case was technically challenging, compounded by the full extent of the shoulder injury only becoming apparent during the operation. Therefore, it was felt that a particularly strong plate was required and a Synthes four-hole right locking compression medial proximal tibial plate was chosen as the most appropriate form of fixation (figure 2). Intra-operatively it was noted that there was severe soft tissue/muscle injury around the shoulder girdle in addition to the scapula body fracture.

Post-operatively, the patient was instructed to use a broad arm sling for 6 weeks and to remain non-weight bearing. The patient was discharged once all other injuries had been appropriately managed.

\section{OUTCOME AND FOLLOW-UP}

At the 3-month follow-up from the date of injury, the patient was found to have a subluxed left shoulder. In addition the tibial plate had cut out (figure 3 ).

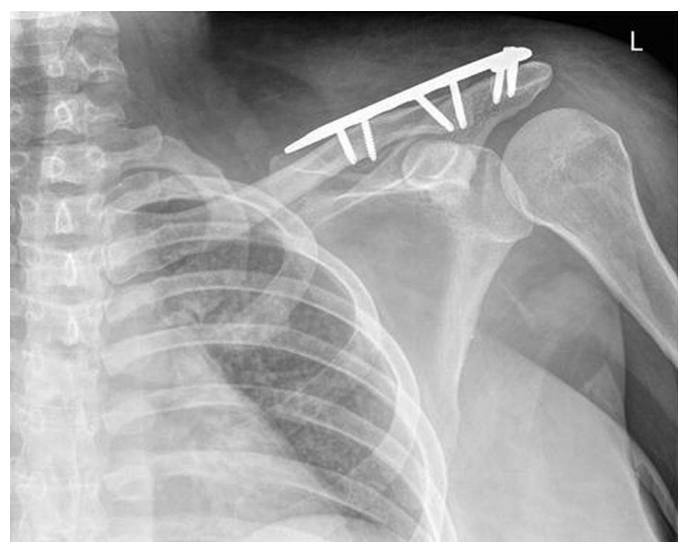

Figure 2 Left anterior-posterior shoulder radiograph demonstrating the left acromioclavicular (AC) joint has been stabilised with a superior fixation plate. There is still on-going slight widening of the left $A C$ joint. The left humeral head is enlocated.

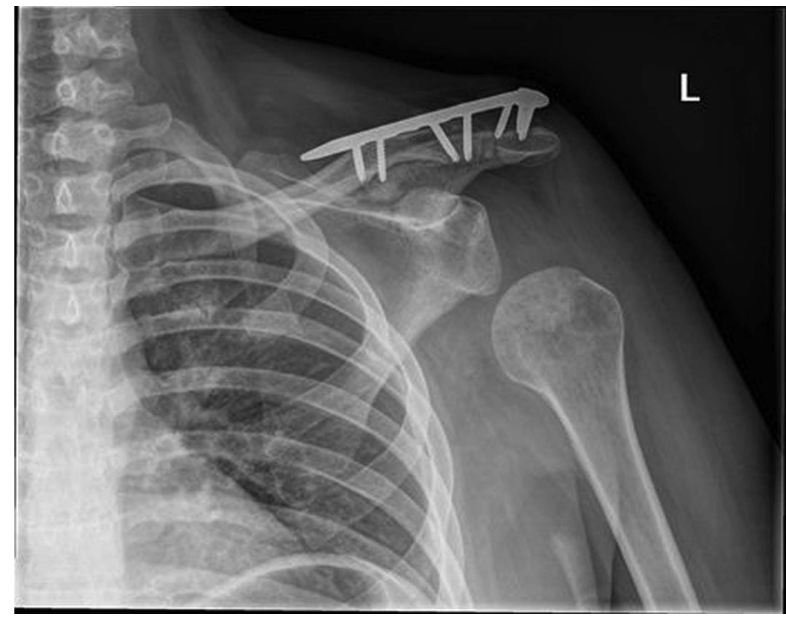

Figure 3 Left anterior-posterior shoulder radiograph demonstrating the superior fixation plate traversing the left acromioclavicular (AC) joint that has cut out distally. The left AC joint being enlocated. The left scapula is also in a satisfactory position. Marked inferior subluxation of the left humeral head evident, but there is no dislocation.

Examination at the time revealed deltoid atrophy, sensory change in the axillary nerve distribution, and motor weakness with shoulder abduction $1 / 5$, elbow flexion $3 / 5$ and elbow extension 3/5. Electromyography was performed which demonstrated axonal injury to the upper trunk of the left brachial plexus with evidence of on-going re-innervation.

The plate was subsequently removed and the AC joint was found to be stable intra-operatively. Physiotherapy was commenced to improve muscle strength and range of motion. Strength and sensation gradually returned.

At 12 months (figure 4) post-injury, the patient was pain free and could complete all her activities of daily living without impediment. On examination she had full bilateral shoulder range of motion, upper limb strength bilaterally was $5 / 5$, and minor sensory change remained over the left lateral shoulder (axillary nerve distribution). She has returned to playing pool and at 24 months was playing again competitively.

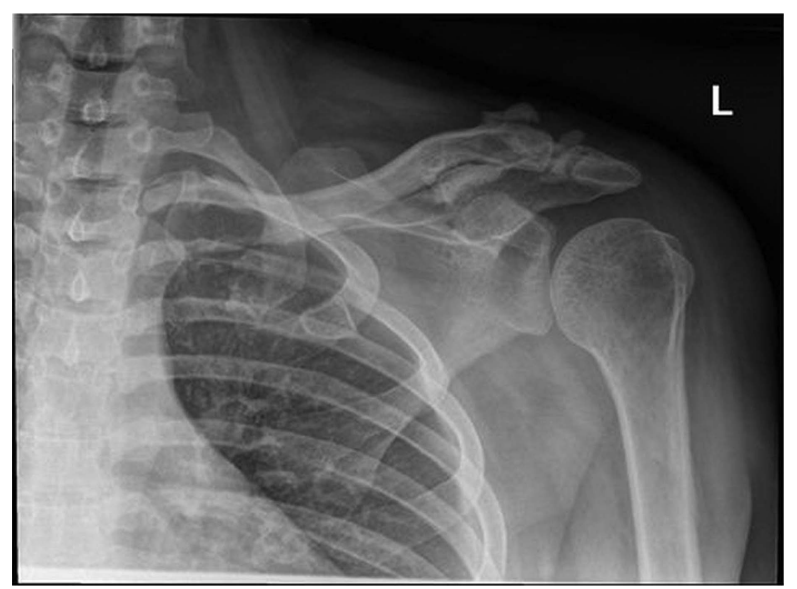

Figure 4 Left anterior-posterior shoulder radiograph. There is new bone formation around the acromioclavicular joint and coracoclavicular ligament without significant interval change. Normal alignment of the glenohumeral joint is seen. 


\section{DISCUSSION}

This case illustrates the importance of early and thorough clinical assessment in a patient sustaining a traumatic injury to her shoulder resulting in a type $\mathrm{V}$ AC joint and brachial plexus injury. The brachial plexus injury became apparent during outpatient follow-up and subsequently resolved over a period of 12 months from the date of injury. Given the patient's multitrauma state, it is likely a complete neurological evaluation was not undertaken or not possible during the admission and subsequently the patient's neurological compromise may have been missed.

The AC joint is a diarthrodial joint located between the lateral end of the clavicle and the medial margin of the acromion process of the scapula. The articular surfaces initially are hyaline cartilage. There is a fibrocartilaginous disk of varying size and shape inside the joint. The majority of motion, which is all gliding, arises from movement of the bones, not from the joint. The clavicle rotates $40-50^{\circ}, 5-8^{\circ}$ of rotation is through the $\mathrm{AC}$ joint, and the remainder comes from scapular rotation. ${ }^{11-13}$ The joint is stabilised via the AC ligament and coracoacromial ligaments with the glenohumeral joint capsule, deltoid and trapezius muscles acting as stabilisers. The glenohumeral joint is a multiaxial synovial ball and socket joint composed of the humeral head and glenoid fossa of the scapula, and is the most mobile joint in the body. The joint is stabilised by the glenohumeral ligaments, glenoid labrum, rotator cuff muscles, biceps and periscapular muscles. The muscles of the shoulder joint complex are innervated via the brachial plexus which is formed by the ventral rami of the lower four cervical and first thoracic nerve roots (C5-C8, T1).

There are a wide variety of surgical treatments for type V AC joint injuries. These include AC repairs, coracoclavicular repairs, combined AC and coracoclavicular repairs, coracoclavicular fusion, and dynamic muscle transfers using the tip of the coracoid process and attached conjoined tendon. ${ }^{7}$ Currently, the most popular methods of stabilisation are coracoclavicular or intra-articular AC repairs. ${ }^{7}$ A common approach is to use small, smooth or threaded Steinmann pins or K-wires to stabilise the joint. $^{71415}$ The use of a hook plate has also been described. ${ }^{16}$ An atypical fixation was used in this case with an adjusted medial proximal tibial locking plate which allowed 3.5 screws in locking and non-locking mode, providing better fixation compared to other implants. The use of such an implant for this type of injury, to the best of the authors' knowledge, has not been previously reported in the literature.

A number of complications may result from operative management of AC joint dislocation, with hardware failure, migration or distal clavicle osteolysis plus AC arthritis being common complications. ${ }^{7}$ Implant cut out was a complication in this case, which may be explained by the rotational movements that occur between the clavicle and acromion. ${ }^{11}$ The patient was obese and there was significant disruption to the surrounding soft tissue structures leading to greater forces, from the upper limb, being placed across the plate/screw fixation. This was also likely to be contributory. Cut out is a known problem with rigid fixation across the AC joint and is one reason why the hook plate was developed. Calcification and ossification of the ligamentous supports of the AC joint was also seen in this case, which has been reported to occur in injured coracoclavicular ligaments up to $40 \%$ of the time. ${ }^{17}$ Usually, it has no effect on the functional outcome. ${ }^{7} 18$

The case adds to the limited literature associating AC joint injury and brachial plexus injury. This observation is consistent with the findings of Sturm and Perry. ${ }^{8}$ They reviewed 59 patients who sustained brachial plexus injuries following blunt trauma, identifying two cases that occurred following acute AC separation. Meislin et $a l^{9}$ also report this association in a patient who developed a brachial plexus neuropraxia 8 years after sustaining a type III AC injury; in this case the patient responded well to coracoclavicular stabilisation.

Further case studies include that by McGahan and $\mathrm{Rab}^{10}$ who report an isolated axillary nerve injury following a fracture of the acromion with an AC separation. Electromyography in this case demonstrated total palsy of the axillary nerve with the injury being identified 2 months after the fracture. Clinically the patient was unable to abduct their shoulder 5 months after injury, but further follow-up was not possible as the patient died of a myocardial infarction. A case description by $\mathrm{McPhee}^{19}$ documents a partial brachial plexus injury following a type VI $\mathrm{AC}$ injury with an associated clavicle fracture, minimally displaced scapula fracture and first-third rib fractures.

Additionally, Das Adhikari et $a l^{20}$ describe a patient who sustained trauma to their right shoulder and trunk after a motor vehicle accident. Injuries included a right AC joint dislocation with a fractured neck and medial border of the scapula with an associated proximal brachial plexus injury in the C5 and C6 nerve root distribution. This case was described as an example of scapulothoracic dissociation, an injury characterised by lateral displacement of the scapula, a severe neurovascular injury, and an injury to the bone (either an AC separation, a displaced clavicle fracture or a sternoclavicular disruption). ${ }^{7}$

Another interesting feature of this case is the glenohumeral subluxation identified 3 months following the shoulder trauma, and subsequent relocation over a period of 6-12 months. Sturm and Perry identified in their study that brachial plexus injuries do occur in association with severe blunt trauma, and they are usually partial palsies and resolve partially or completely in two-thirds of cases. ${ }^{16}$ This information is important when informing the trauma patient about their likely long-term outcomes when brachial plexus lesions are diagnosed.

Our case highlights the importance of neurological assessment following AC joint injury and awareness of the associated potential neurological complications. This is especially important in patients who may have more obvious and distracting injuries where this diagnosis may be difficult and delayed.

\section{Learning points}

- Neurological assessment is essential following acromioclavicular (AC) joint injury.

- Brachial plexus injuries can occur in association with severe trauma to the $A C$ joint.

- These are usually partial palsies and resolve partially or completely.

Acknowledgements The authors thank Katrin Zellweger, BPhysT, MBA.

Competing interests None.

Patient consent Obtained.

Provenance and peer review Not commissioned; externally peer reviewed.

\section{REFERENCES}

1 Emery R. Acromioclavicular and sternoclavicular joints. In: Copeland S. ed Shoulder surgery. London: WB Saunders, 1997.

2 Fraser-Moodie JA, Shortt NL, Robinson CM. Injuries to the acromioclavicular joint. J Bone Joint Surg Br 2008;90:697-707. 
3 Bearn JG. Direct observations on the function of the capsule of the sternoclavicular joint in clavicular support. J Anat 1967;101(Pt 1):159-70.

4 Williams GR, Nguyen VD, Rockwood CR. Classification and radiographic analysis of acromioclavicular dislocations. Appl Radiol 1989;18:29-34.

5 Tossy JD, Mead NC, Sigmond HM. Acromioclavicular separations: useful and practical classification for treatment. Clin Orthop Relat Res 1963; 28:111-19.

6 Rockwood CA. Injuries to the acromioclavicular joint. In: Rockwood CA, Green DP, eds. Fractures in adults. Vol 1. 2nd edn. Philadelphia: JB Lippincott, 1984:860.

7 Rockwood CA, Green DP, Bucholz RW. Rockwood and Green's fractures in adults. 7th edn. Philadelphia, PA: Wolters Kluwer Health/Lippincott, Williams \& Wilkins, 2010:1210-42.

8 Sturm JT, Perry JF Jr. Brachial plexus injuries from blunt trauma - a harbinger of vascular and thoracic injury. Ann Emerg Med 1987;16:404-6.

9 Meislin RJ, Zuckerman JD, Nainzadeh N. Type III acromioclavicular joint separation associated with late brachial-plexus neurapraxia. J Orthop Trauma 1992;6:370-2.

10 McGahan JP, Rab GT. Fracture of the acromion associated with an axillary nerve deficit: a case report and review of the literature. Clin Orthop Relat Res 1980;147:216-18.

11 Rockwood CA, Williams GR, Young CD. Injuries to the acromioclavicular joint. In: Rockwood CA, Green DP, Bucholz RW, Heckman JD, eds. Fractures in adults. Vol 2 4th edn. Philadelphia: Lippincott-Raven, 1996:1341-414.
12 Codman EA. Rupture of the supraspinatus tendon and other lesions in or about the subacromial bursa. In: Codman EA, ed. The shoulder. Boston: Thomas Todd, 1934:32-65.

13 Flatow EL. The biomechanics of the acromioclavicular, sternoclavicular, and scapulothoracic joints. AAOS Instr Course Lect 1993:42:237-45

14 Lizaur A, Marco L, Cebrian R. Acute dislocation of the acromioclavicular joint. Traumatic anatomy and the importance of deltoid and trapezius. J Bone Joint Surg Br 1994:76:602-6.

15 Fama G, Bonaga S. [Safety pin synthesis in the cure of acromio-clavicular luxation]. Chir Organi Mov 1988;73:227-35.

16 Habernek H, Schmid L, Walch G. [Management of acromioclavicular joint dislocation with the Wolter hook-plate. One year follow-up of 35 cases]. Unfallchirurgie 1993;19:33-9.

17 Nuber GW, Bowen MK. Acromioclavicular joint injuries and distal clavicle fractures. J Am Acad Orthop Surg 1997;5:11-18.

18 Hessmann M, Gotzen L, Gehling H. Acromioclavicular reconstruction augmented with polydioxanonsulphate bands. Surgical technique and results. Am J Sports Med 1995;23:552-6.

19 McPhee IB. Inferior dislocation of the outer end of the clavicle. J Trauma 1980;20:709-10.

20 Das Adhikari D, David SS, Kumar GR. Scapulothoracic dissociation-a case report. J Indian Med Assoc 2006;104:334-5.

Copyright 2014 BMJ Publishing Group. All rights reserved. For permission to reuse any of this content visit http://group.bmj.com/group/rights-licensing/permissions.

BMJ Case Report Fellows may re-use this article for personal use and teaching without any further permission.

Become a Fellow of BMJ Case Reports today and you can:

- Submit as many cases as you like

- Enjoy fast sympathetic peer review and rapid publication of accepted articles

- Access all the published articles

- Re-use any of the published material for personal use and teaching without further permission

For information on Institutional Fellowships contact consortiasales@bmjgroup.com

Visit casereports.bmj.com for more articles like this and to become a Fellow 